THIS VERSION IS NOT FOR CITATION

PLEASE CHECK AGAINST FINAL VERSION

https://doi.org/10.1016/i.erss.2021.102210

\title{
Social License to Automate: A Critical Review of Emerging Approaches to Electricity Demand Management
}

Sophie Adams ${ }^{\mathrm{a}}$, Declan Kuch ${ }^{\mathrm{b}}$, Lisa Diamond ${ }^{\mathrm{c}}$, Peter Fröhlich ${ }^{\mathrm{d}}$, Ida Marie Henriksen ${ }^{\mathrm{e}}$, Cecilia Katzeff $^{\mathrm{f}}$, Marianne Ryghaugg, Selin Yilmaz ${ }^{\mathrm{h}}$

a. School of Humanities and Languages, University of New South Wales, Kensington NSW 2052, Australia, s.m.adams@unsw.edu.au (corresponding author)

b. Institute for Culture and Society, Western Sydney University, Penrith NSW 2751, Australia, d.kuch@,westernsydney.edu.au

c. Austrian Institute of Technology, Giefinggasse 4, 1210 Vienna, Austria, Lisa.Diamond@ait.ac.at

d. Austrian Institute of Technology, Giefinggasse 4, 1210 Vienna, Austria, Peter.Froehlich@ait.ac.at

e. Department of Interdisciplinary Studies of Culture, Norwegian University of Science and Technology, NO-7491, Trondheim, Norway, ida.marie.henriksen@ntnu.no

f. KTH Royal Institute of Technology, SE-10044, Stockholm, Sweden, ckatzeff@,kth.se

g. Department of Interdisciplinary Studies of Culture, Norwegian University of Science and Technology, NO-7491, Trondheim, Norway, Marianne.ryghaug@ntnu.no

h. University of Geneva, 24 rue de Général-Dufour, 1211 Genève 4, Switzerland, Selin.Yilmaz@unige.ch

\begin{abstract}
Electricity demand-side management (DSM) programs are becoming increasingly important to energy system managers in advanced industrialized countries, especially those with high renewable energy penetration. As energy user participation is paramount for their success but has proven to be difficult to obtain, we explore the usefulness of the 'social license' concept, originally developed in the mining sector, to refer to the process of creating acceptance in DSM programs aimed at managing or controlling household energy resources such EVs, batteries, and heating and cooling devices. We argue that analyzing the attainment or lack of 'social license' may be useful to energy policy-makers and researchers for understanding public concerns with not only supply-side energy resources, but also DSM. We do so by (1) drawing attention to potential frictions between demands for flexibility on the one hand and social practices and habits on the other; (2) attending to the ways that users'
\end{abstract}


engagement in DSM programs is influenced by their sense of control and agency, and their trust in program providers; and (3) exploring the ways that users may understand their stake in the energy system and may participate in programs as collectives rather than simply as individuals. We argue that a 'social license to automate' could not only describe a set of tools to manage participation in DSM projects, but rather assess the ways users effectively feel part of new energy systems designed to serve them.

\title{
Key words
}

automation, energy, smart grid, demand side management, acceptance, social license

\author{
Abbreviations \\ DLC Direct Load Control \\ DSM Demand Side Management \\ EV Electric Vehicle \\ HEMS Home Energy Management Systems \\ HVAC Heating, Ventilation and Air Conditioning \\ ICT Information and Communications Technology \\ IoT Internet of Things \\ PV Photovoltaics \\ SLA Social License to Automate \\ SLO Social License to Operate \\ STS Science and Technology Studies
}

\section{Acknowledgements}

This publication received funding from the Australian Renewable Energy Agency (ARENA) as part of ARENA's International Engagement Program.

\section{Introduction}

In post-industrial societies, such as those in Europe and North America, the transition towards renewable energy systems has brought about a new interest in involving users in energy system operation [1]. The intermittency and variability of renewable energy sources, especially wind and solar, has led policy-makers and system operators to propose a change in the use of demand-side 
management (DSM) $)^{1}$ tools in favor of more automated solutions. These include a range of automation technologies from direct load control (DLC), which involves the remote control of household systems and appliances such as heating and ventilation systems and electric vehicle (EV) charging via a third party provider (e.g. utility company), to the management of appliances via a Home Energy Management System (HEMS), or manual automation of appliances based on price signals. By requiring energy users to provide far greater levels of flexibility in their everyday use than previously asked of them, this is likely to change the role of households in the energy transition. The impact on users of providing flexibility can vary greatly depending on the technology and automation level in place but, irrespective of noticeable changes in energy availability in everyday life, there is more to getting end-users on board than the question of perceived inconveniences. That is, automation raises the issue of how problems in the electricity sector are negotiated as either individual or collective challenges and who benefits from either framing.

By reviewing the academic literature on the conditions in which energy users accept automation of their household energy use, this paper critically investigates the role of a 'social license to automate' (SLA) in DSM in enabling this move. The concept of a SLA is both novel and valuable: it provides a framework to understand the (mis)alignments between the expectations of actors within the energy system on the one hand, and household practices, sense of control and stake in the energy system, on the other. These domains of energy practices and energy users' engagement with technologies and other actors have largely been considered separately. The concept of an SLA bridges them by making explicit the negotiations between households and energy system planning that are necessary within each.

The 'social license' concept is based on a 'social license to operate' (SLO), which was developed through experiences in the mining sector and refers to the extent to which an initiative has the approval or acceptance of communities of stakeholders and captures a cluster of factors beyond that of formal legal approval which can shape its reception [2]. In the context of energy systems, the concept of a 'social license' appears to sit between the formal and informal rules of conduct for the electricity companies, grid operators and network businesses trialling automation in DSM.

Our analysis of the literature begins with the proposition that, in many jurisdictions, the flexibility of energy use is or will be an important and highly prized new economic and security resource within energy systems. Utilities and network operators see demand flexibility as increasingly necessary for the operation and planning of power system stability, power system frequency and to manage localized network congestion and voltage issues [3,4]. Enthusiasm for DSM is driven by the imperative to maintain steady frequency levels from an overall system perspective, despite the increased proportion of intermittent renewable power in the electricity generation mix [5]. From a more local perspective, new DSM tools are also being designed to manage voltage issues related to increased stochasticity and bi-directional electricity flow caused by rapidly increasing distributed power generation (e.g. rooftop solar panels) [6,7]. They are also designed to enhance load management in order to decrease the congestion in the grid associated with the adoption of heat pumps and EVs in distribution networks or other peak demand issues during heatwaves and extreme weather events $[8,9]$.

\footnotetext{
${ }^{1}$ Demand-side management (DSM) refers to all changes that originate from the demand side of the market in order to achieve large-scale energy efficiency improvements by deployment and use of improved technologies and changes in end user behavior or energy practices.
} 
For energy policy-makers (rule-makers, system operators, compliance agencies and other governing bodies), valuing this new resource of flexible electricity loads is an increasingly important challenge. Blackouts and other interruptions to electricity supply are costly disruptions - consider refrigerated food spoiling, heating and cooling systems shutting off, and health care devices, lighting and computing systems going dark. In response, flexibility programs have been developed with a view to making social practices, values and habits around energy use manageable for electricity system operators in similar ways to the physical energy supply assets that have been their traditional purview.

A central animating problem for building user flexibility as a resource is the development of devices to enact new pricing systems and other tools to economize energy resources [10] as the energy needs of users must be balanced with the supply of the system. The roll-out of DSM technologies may prove to be more complicated than other system reforms, such as those around technical requirements for new supply, because users have not responded enthusiastically to their enrolment in new DSM programs by policy-makers and engineers $[11,12] .^{2}$

When trying to understand how best to create resources such as user flexibility and flexible electricity loads, insights may be drawn from other sectors that have been preoccupied with resource extraction for decades. In the mining and resources sectors, it has been recognized in recent decades that these energy resources and mineral commodities are not simply discovered, but made available for extraction by gaining and maintaining a SLO [14-16]. Thus, the concept of 'social license' may be instructive for the process of gaining a social license to automate flexible loads and a basis of institutional innovation in managing the interplay between energy users, system operation and the governance of the new flexibility resources.

This review focuses on the literature around energy demand management to consider existing affinities with the social license concept to make such links explicit. We critically examine the issues of user capacity, sense of control and broader governance problems in conceptualizing users' engagement with DSM. Relationships between those seeking acceptance of DSM programs - both formally and informally through a 'social license' - and users must be developed carefully. Further, flexibility is not just a tradeable resource but a capacity to change energy use. Thus, our goal is not simply to apply the concept of social license to this new energy resource, but to treat the concept as a 'sensitizing concept' [17] to consider forms of interaction between energy users, technology developers and system operators.

Section 2 outlines the rationale for developing new DSM technologies and associated frictions with energy user practices, before turning to the ways literature on the development of a SLO in the mining sector sensitizes us to the development of new 'resources' from demand flexibility. Section 3 identifies three prominent issues, namely i) the capacities of the user that the automation of flexibility hinges on; ii) the user's sense of control and agency when participating in DSM programs, and their trust in program providers; and iii) the stake of users in the management of the electricity grid, which overlap with concerns in the extant social license literature on mining and can be considered core themes in a SLA. Section 4 concludes with the insights that can be drawn from the review, followed by a discussion of the limitations of SLA and future research needs as they relate to issues of capacity and justice beyond the scope of this review.

\footnotetext{
2 This does not imply a binary between 'real' supply resources and 'uncertain' demand-side resources. As Kama and Kuchler [13] stress, resource-making is a form of 'ontological politics' - a way of enacting relations between people and things that has political consequences. Resources could be made otherwise or even be unmade if circumstances change as is clear in the emerging terrain of DSM we document in this paper.
} 


\section{Automation and energy users}

\subsection{Residential automation as an emerging smart grid issue}

Our starting point in debates about the prospects for automating residential electricity loads is the idea that user flexibility is emerging as an increasingly important resource for policy-makers and system operators. This interface between users and technologies is not only a question of technology design but a social and political issue insofar as DSM technologies are becoming increasingly important tools in ensuring the stable provision of electricity. The central objective of DSM is to alter the quantity and timing of energy use in order to ensure that demand does not exceed supply, particularly at peak demand hours of the day and in conditions of particular pressure on the electricity grid as well as shifting demand towards periods of high power generation from intermittent energy resources. This is an inversion of the expectation that supply must be adjusted to meet demand, which has dominated the history of the electricity system [18]. Matching demand to supply in this way is seen to be possible by making energy use more flexible, typically in the form of load 'shifting' - that is, moving energy use to a different time of day - or load 'shaving' - that is, reducing the amount of energy used within a certain period. Energy users' flexibility, which refers to a capacity and willingness to adjust the timing and/or size of the household load, and along with it the practices and values (including e.g. comfort and convenience) that are associated with energy consumption, has thus become a key element of smart grid imaginaries [19-22]. In this way, household conduct and energy system governance are explicitly linked [23].

Flexibility of demand is widely expected to be achieved in one of two main ways: 'either as a matter of consumer choice or as something that suppliers can achieve behind the scenes' [24, p. 9]. The former 'choice'-based perspective refers to behavioral demand response to provided information, such as feedback or price signals, in which householders manually adjust their energy usage, sometimes in real time. These signals do not require a firm commitment by the user, and instead leave response to the user's discretion. The 'behind-the-scenes' alternative, which is receiving increasing attention in the energy sector, is the automation of energy demand.

Although there is a long history of automation in professional and industrial settings [25], its application in everyday contexts is more recent. A notable attempt to provide a structured description of automation in demand-side energy systems has been provided by Karjalainen [26]. Based on the taxonomy established by Sheridan and Verplank [27], they propose four levels of automation, beginning with (1) full manual control, which offers users a complete set of action alternatives to choose from; (2) offering users a narrowed-down selection to choose from; (3) executing one alternative but notifying the user and providing them with the option to veto it; to (4) full automation, which does not involve or inform the user. In the energy demand context, these four levels of automation can be facilitated by HEMS or 'smart homes', which can coordinate a number of loads according to various parameters selected by the householder, including preferences for comfort and amenity (such as temperature) as well as preferences regarding the energy used (such as price and source). The higher levels of automation in this taxonomy are achieved by DLC initiatives, which usually involves utilities remotely adjusting the household load by switching on and off specific devices and appliances such as heat pumps, boilers, white goods, heating, ventilation and air conditioning (HVAC), charging for EVs, etc., usually for a specific time period.

Our attention is focused on automated DSM initiatives. However, DSM initiatives are not always easily distinguished from different types of more 'manual' DSM systems or mixtures of such systems. 
Part of this entanglement is attributable to issues of control and the significance of the possibility to manually override automated systems that we discuss below. As behavioral change strategies are increasingly perceived to have failed to fulfil their promise of mobilizing users to engage in manual demand response [28,29], automation is viewed as a means to overcome the 'engagement deficit' [19]. It is seen by DSM program designers as a way to 'negate' user 'apathy' and circumvent the challenge posed by the largely habitual nature of household energy consumption behavior [28] by making demand response 'sufficiently effortless that little or no engagement is required by the user' [29, p. 181]. It is thought that where 'automation takes over for providing load flexibility, we will not have to rely on the particularities of the individual users in order to achieve it' [20, p. 288], while users for their part may simply 'set it and forget it' [30] - whether by signing up to a DLC scheme or programming their energy consumption preferences in the smart home. Proponents of automation present it to policy-makers, energy users and system operators as a viable alternative mode of demand management because it is thought to not depend on, and appears to circumvent, the engagement by the user that behavioural demand management has not achieved. Research on automated DSM trials and programs to date indeed bears out this promise of the potential for load shifting and shaving through automation to some extent. For example, reviews indicate that automation increases the level of peak shaving for all types of variable tariff except for real-time pricing [31]. Furthermore, a review of the response rates in the form of demand reduction from 16 trials and programmes found that the average response rate of 16 trials was $28.2 \%$ and $12.8 \%$ with automation and without automation, respectively [32].

In many parts of the world, however, moves towards the 'smart grid', including the installation of technologies such as smart meters, which are a prerequisite for many types of automation in DSM, have been met with controversy and resistance [33]. The 'sparse but growing' [34] research literature on the acceptability of distributed energy systems suggests that the extent of, and reasons for, a lack of acceptance by users are highly conditional on context. It reports 'neither overwhelming support nor opposition' to smart metering [35, p. 89] or DSM [36]. Where there is resistance in the case of in-home or real-time displays, for example, it is not a 'wholesale rejection' but a more ambivalent position [37, p. 8]. Householders express diverse expectations and considerations in relation to the smart grid [38]. Similarly, reports of trials of automation technologies in DSM, as well as studies that have examined participant responses to the prospect of various automation applications, offer a mixed and complex picture of user acceptance. Overwhelmingly, studies suggest that full automation without user override and intervention opportunities is considered problematic by users [39]. Many of users' concerns about DLC and other automated programs are articulated with reference to a lack of trust in energy companies.

The emergent concerns about agency and control over devices underscore the novelty of the ethical terrain of household automation as a new socio-technical space being navigated by grid operators, intermediaries and households. So in order to successfully establish automated DSM as a means to achieve a more sustainable energy system it is therefore vital to continue to build a better understanding of the circumstances and conditions of users' acceptance and resistance to automation for DSM. There is growing acknowledgement based on trial experiences as well as insights from the critical literature that the key to success is not technology alone, but also user engagement and close attention to how users are included in pilots and trials of automated technologies [40]. The extent to which the expectations of program designers and the interests and experiences of users align, appears to be decisive. Failure to implement automated DSM is likely to occur when program designers do not meet consumer needs [31]. 


\subsection{From 'social license' to mine to 'social license to automate'?}

The concept of a SLO first emerged in the forestry and mining sectors in the 1990s to refer to the social conditions necessary for the success of a resource project [14]. The concept developed around a set of measures and stakeholder engagement practices to express 'an intangible, impermanent indicator of "ongoing acceptance of a company's activities by communities" [41, p. 264], and to offer a way to account for instances of resistance, in which the license can be said to be lacking or lost. The flexibility around defining the community affected by any one project or industry is arguably part of the appeal of the concept [42]. The use of concepts like SLO has become increasingly commonplace in Australia, Canada, the USA and other 'advanced liberal democracies'. For example, resource companies in Australia [16] have increasingly deployed the term to describe their relations with publics; whilst nuclear waste managers, wind farm developers [43] and many other primary industries have adopted the concept in seeking to address concerns not captured through formal legal channels [42]. Several elements common to the use of the concept by industry engagement and 'Corporate Social Responsibility' officials and peak body representatives include:

(1) 'that SLO goes beyond regulatory approval and consent conditions to incorporate wider publics who can affect the profitability of a project;

(2) that SLO does not indicate universal agreement, but could exist along a continuum of approval, acceptance and support from various publics ranging from rejection or withdrawal to 'psychological identification' with the goals and ambitions of a project. At this highest level project and societal interests are seen to align;

(3) that any separation between the immediate community surrounding a project and a wider set of stakeholders and publics is fragile.' That is, otherwise idle neighbors to a project may become activists under certain conditions [16, p. 5].

These elements of an SLO sensitize us to the scope of automation projects as well as the character of the resource of flexibility, for which proponents seek a 'social license'. Regarding scope, elements (1) and (3) highlight the need to think beyond mere 'users' of a technology - particularly those involved in pilot projects - and instead consider wider publics, such as other energy users. The character of DSM and other automation technologies sees user practices constitute the very resource at stake in discussions of a social license. These elements also sensitize us to ways in which the perceived roles and stakes of various actors can misalign.

The continuum of public support, or element (2) above, sensitizes us to the fact that the prospects for flexibility as a resource and user acceptance of the ambitions of a project are inextricably linked. Many DSM programs involve visualization and monitoring of household energy consumption as means to encourage energy users' acceptance of and identification with the need to alter their consumption and a framing of energy 'demand' as a problem - a form of 'psychological identification' by users with energy system goals. However, acceptance can be partial and/or provisional, giving rise to another form of misalignment between the expectations of actors within the energy system and those of households.. For example, once automation technologies are rolled out, some users may withdraw full support and only accept automation over appliances during some periods.Considering our aim is to socialize the development of DSM by enlarging the scope of those considered to be involved, two key strands of literature on SLO are notable: the first takes its point 
of departure in the need for deliberating the issues created by mining projects, some anticipated and others not [14,44,45]. In Boutilier and Thomson's [14] influential analysis, emblematic of this first approach, it is the publics or communities that grant a social license. This more issue-oriented approach to an SLO can be distinguished from a second approach: one emphasising general public opinion whereby it is 'the public' that grants a social license in ways that interact with political and regulatory processes at the level of the nation-state, rather than project areas [14,15,42]. Both strands of literature rely on quantitative scaling of public opinion according to a continuum from 'withholding' to 'psychological identification'. This spectrum sensitizes us to both the issues created during the process of making energy user flexibility, such as the likelihood of unexpected problems leading to user hesitancy about DSM. In the case of the Bolivian San Cristobal Silver-Lead-Zinc mine examined by Boutilier and Thomson, support dipped markedly during the construction phase, for example [14].

Furthermore, the SLO literature sensitizes us to the governance of resources, including how expectations of fairness manifest as institutions and to the ways diverse institutions are necessary to construct its legitimacy. Social license practitioners across these streams have largely imagined the 'social' dimension of the license as something granted at the intersection of people, resources and political power in the context of global supply chains of commodities, especially minerals and precious metals. For example, the San Cristobal mine case shows that international mining companies 'discovering' new value in silver, especially, emerged from new political situations in Bolivia during the 20th Century. An extractive push from national governments and neoliberal allies in the USA brought with it mining capital that prompted negotiation with local actors to access land and address issues around tailings, llama herds and local housing pressures, especially during an expansive construction phase [14].

Automated electricity DSM also demonstrates that valuation is contingent on institutions beyond the market, although these differ from commodities such as silver. The former case, complex sociotechnical assemblage of users and technologies in regionally or nationally managed electricity grids turn the automated control of electrical devices into a commodity. Thus, the ethical and social space of DSM is quite different to mineral commodity extraction because the electricity users' flexibility is the commodity [46]. While minerals and extracted fuels can be stored, electricity, as Kester [46, p. 206] summarizes, 'is transported across insulated wires in a continuous and all-pervasive network that links production with consumption instantaneously [...] The unique characteristic of electricity grids and their currents (the flow of electrons) is that input and output are constantly balanced towards a particular voltage and frequency. The moment [electricity is used by charging an EV or switching on an air conditioner], somewhere along the grid more electricity needs to be produced, recovered from storage, or "won" by postponing other demand".

This temporal and technological specificity means that a SLA requires distinctive discussion of not only publics that are affected, locally, as they dwell in the vicinity of a resource extraction plant (a coal mine, a wind park, etc.), and how acceptance might be achieved with or withdrawn by such publics. The multi-scale complexity of electricity system governance - the requirement to manage resources in milliseconds, minutes, hours and multi-decadal increments - underscores the complexity turning electricity use across multiple sites into a resource. For this reason, we examine, in turn, (1) the capacities of users, especially how much households can alter the quantity and timing of their 
energy use; (2) the user's sense of control and agency when participating in DSM programs, and their trust in program providers; and finally (3) users' stake in the management of the electricity grid. A SLA, we propose, must consider all three dimensions.

\subsection{Methods and scope of review}

In this research, we undertake the approach of 'narrative review' [47], providing an exploratory evaluation of the literature of automated DSM. The review is organized by extending the concept of SLO to SLA using the latter as a 'sensitizing concept' [17, p. 7]. Thus, the social licence concept functions as an analytic lens that offers ways of seeing, organizing and understanding the experiences in the field of automated DSM, rather than using it as a definitive concept or one which could provide guidelines on how to apply or grant a 'social license' for automated DSM projects to energy firms and/or to resolve the legitimacy issues introduced by new automated DSM technologies.

The review is conducted by an interdisciplinary group of researchers participating in a research collaboration within the User-Centred Energy Systems Technology Collaboration Programme of the International Energy Agency. The first step was to conduct searches and collect literature in a common Zotero library with labels on contents. The searches were performed through bibliographic databases mainly from Scopus, Web of Science, Taylor \& Francis, and popular search engines (e.g. Google Scholar) to select peer-reviewed academic literature including journal articles and conference papers, reports, and published books. We included studies written in the English language that documented empirical, qualitative and quantitative findings of different forms of automated DSM. The following types of studies were excluded from the review paper; i) studies that focused on nondomestic sectors (e.g. services and industry), ii) documented non-empirical results (e.g. modelling) and iii) studies that focus exclusively on manual or behavioral DSM (e.g. electricity tariffs, other incentives for households to undertake load shifting or shaving).

The review does not define a specific geographical scope, but the studies conducted are mainly from Western societies, reflecting the relatively higher number of articles on DSM in these regions. The focal time span is the last ten years, but we have included some prominent articles from before that period, to give a broader view of the learnings of the field. Once all relevant literature was collected, we used the SLA as a way of organizing the literature review, sensitized to the relationship between energy users' practices and the prospective resource of flexibility. We were moreover sensitized to the potential for households and other actors' expectations about the realisation of this resource to differ and, indeed, to clash.

\section{Towards a social license to automate?}

In this section, we discuss three critical emerging themes in the energy social scientific literature in order to make the case for the usefulness of the concept of a SLA that builds upon or reflects the problems identified in the mining SLO literature. The latter, especially through its emphasis on stakeholder governance, underscores the collective nature of resource valuation, stressing the interdependence of corporate operations with wider communities.

\subsection{Accounting for capacities to shift household energy use: making flexibility resources}

Far from bypassing the need for user engagement, the automation of DSM in fact depends no less on engagement - but requires different kinds of engagement. This distinction is crucial to understanding 
the constructed nature of both flexibility as a resource and the attempts to align user practices with DSM project objectives, such as grid stability. As discussed below, there is some evidence to suggest that in some conditions users welcome automation to relieve them of the labor of achieving flexibility manually. However, a growing critical literature has observed how the construction of disengagement associated with automation ignores the kinds of engagement required for automation to succeed and neglects the ways that automation affects the home [29]. Yolande Strengers has argued, for example, that the 'seemingly contradictory' impulses of active consumption and passive automation in fact constitute a 'united vision' of the energy consumer she describes as 'Resource Man' [48]. Strengers' critique of 'Resource Man' resonates with the highest level of a social license granted during resource extraction - 'psychological identification' between the community and objectives of the extractive project. From the SLO literature, citizens speaking of being residents of a 'mining town' [14, p. 47] reflects the unity of purpose underpinning resource planning in the electricity sector pertinent to a SLA.

This subsection discusses the scope to achieve demand flexibility through automation in light of the existing experiences of behavioral demand response. We show that accounting for capacities to shift household energy use has required ongoing processes of negotiation through projects to 'discover' where flexibility resources lie within social practices. The existing literature has shown that engagement in DSM initiatives depends on a willingness and capacity to reconsider and reconfigure energy consumption practices to achieve the flexibility necessary for load shifting and shaving [49]. Many studies report that at least some of the householders participating in DSM programs experience the changes to their household practices associated with load shifting as inconvenient and disruptive, and are therefore unwilling to undertake these changes [50]. The practice theoretical literature on energy consumption suggests that some practices are less malleable and available to rearrangement than others [51,52]. It has illustrated the ways in which 'daily and weekly schedules are defined by collective social and temporal rhythms, not by individual choice', implying that 'people are not free to re-arrange the timing of energy demand at will' [24, p. 2; emphasis in original] [see also 53-55]. Based on insights from behavioral demand response programs it appears that practices that are more widely or more successfully rescheduled for non-peak demand periods include laundry, household chores and dishwashing, while entertainment, lighting and cooking - of the evening meal in particular - are considered to be less flexible [22,51,55-57]. Research participants in studies have raised concerns about possible disruption to important practices such as family mealtimes [56,58,59], for example, but also expressed greater openness to temporary household load limits when presented with the possibility to exclude times of the day or practices considered 'essential' [60]. These literatures have pointed to the limits of the flexibility of household energy load, suggesting that such limits exist where people perceive that energy use - at least at specific times and for specific functions - is necessary and non-negotiable [59,61].

Indeed, to the extent that energy users are open to load shifting and shaving where it involves minimal reconfiguring of practices and associated sacrifice of comfort or convenience [55], there appears to be a role for automation. Automation is seen to 'take over some of the planning otherwise left to the householder' [49, p. 40], allowing people to maintain their daily rhythms and routines while their smart appliances respond to changing network conditions, including to real time tariffs that change too frequently and unpredictably to respond to manually [56,61]. Householders may in fact prefer automated to manual energy management, for example, as found in an EV charging trial in Denmark in which 'manual plug-in practice was generally experienced as [...] something extra to do and remember' [59, p. 128]. In some cases, participants reported feeling safer when experts controlled 
their heat pumps [62]. DLC of appliances may further minimize disruption by making load shifting 'invisible' [24] and may be deemed acceptable provided that it does not result in any perceptible changes in temperature or other measures of comfort and convenience $[35,61,63,64]$ and that users are adequately compensated for the inconvenience [65].

It would therefore seem that automation may achieve demand flexibility on behalf of the energy user, minimizing the discomfort and inconvenience associated with load shifting and shaving, as long as comfort and time constraints are adequately considered. However, users may meet automated DSM with concerns similar to those associated with behavioral demand response as indicated above, and some research participants have also expressed 'fears about the time and energy required' to manage the automation technologies themselves [56]. Crucial to building a SLA is therefore that the design of automated DSM programs takes into account insights from the experiences of behavioral demand response programs about the social constraints including habits, labor and institutional constraints to load shifting and shaving, as well as addressing concerns or challenges of automation specifically.

The observations outlined above suggest that the potential for automated load flexibility may be applicable to only some energy consumption practices and time frames. The literature also suggests that not all households are equally placed to participate in automated DSM. The concept of flexibility capital, which refers to the ability to shift energy use in time and space, opens up analysis of the uneven distribution of such ability and the issue of flexibility justice [66]. Flexibility capital is determined by everyday practices but also by other factors such as the energy storage capacity, culture and religion [67], life stage, and wealth of householders. Automation technologies are indeed a component of flexibility capital - and tied in part to economic characteristics - given that only some households have the means to purchase smart appliances and HEMS, for example, to make their energy use flexible [68]. One consequence of this is captured in the idea of 'flexibility woman' who takes on the burden of providing flexibility if the household is unable to afford smart home equipment $[69,70]$. This means that automated DSM programs must be tailored to accommodate the different capacities of households to participate, as well as the varying scope for flexibility associated with different energy practices. This is necessary if automated DSM programs are to be successful - and if they are to not deepen existing inequities between households.

Attention is also required regarding the indirect and potentially undesirable effects of automating flexibility. For example, practice theorists have observed that the use of smart appliances including washing machines and dishwashers, which allow householders to pre-program the cycles of these appliances for off-peak periods such as the middle of the night, may have a number of negative implications. These include changes to the busy weekday morning routine associated with the additional task of hanging out laundry, the disturbance associated with noise during the night, and the possibility of bacterial growth and unpleasant smell of newly washed laundry left in the washing machine for several hours [59], as well as potential conflicts with household insurance companies in the event of water damage occurring from an automated washing cycle that was active while residents are not at home. Studies have also shown that many seem to perceive increased risks, such as fire hazards from devices operating during night times, even though technically hazards may be reduced when appliances are being operated automatically [71]. Some studies show that DSM challenges dynamics among the members of a household, for instance creating conflicts between partners, or between parents and children, about changing household practices [72]. These experiences suggest that the acceptability of automation in DSM depends on the perception that automation will not cause 
the kinds of disruptions or other detrimental effects in households that are created by more manual forms of DSM engagement. Furthermore, such pilots underscore the insight from the mining and resources literature that a social license requires ongoing monitoring throughout the lifecycle of the project as expectations meet new realities: the smell of musty washing impacting an SLA or housing pressures during the construction phase of a mine impacting an SLO.

The observations outlined here indicate that, while automation technologies - particularly those that make DSM 'invisible' - may circumvent the need for some user engagement, the success of automation for DSM depends no less on the willing engagement of the user. This means that users still need to be convinced that there is a worthy cause and that expected benefits will outweigh any negative consequences, putting the communicated rationale in the spotlight. Indeed, a participant from a trial of load shifting of space heating questioned whether the benefits outweigh the negative effects when they stated, 'I care very much about the environment and save electricity in every way I can, but it doesn't feel worth freezing every day throughout the winter' [73, p. 11]. It has been shown that mixing rationales in a one-size-fits-all approach can be detrimental in reaching users [74], suggesting that targeted value framing that applies altruistic, biospheric, and hedonistic messages in a selective manner, could be a key component in recruiting more consumers to participate in flexibility programs. The literature reviewed above also shows that, while automated DSM may make load shifting and shaving more easy and less disruptive, it can still have various impacts on the household. What is more, it encounters other challenges where householders perceive it as an encroachment on their control over energy use in the home, as discussed in the following section. This perceived encroachment means that acceptance may be partial or provisional, and underlines the importance of the energy industry understanding the context and substance of household practices that are the object of DSM. 'Psychological identification' with the objectives of DSM, in other words, is both dynamic and situated in household practices.

\subsection{The user's sense of control}

Intimately related to the accounting for capacities across the lifecycle of DSM trials and programs are issues arising from the moving boundary between user and automated control over devices. The scope, size and availability of DSM capacity as a resource for system operators can be compromised by an unwillingness observed on the part of energy users to cede control to a third party through automated DSM [36,50,75], particularly through DLC [56,61]. Such concern about loss of control is partly associated with the subsequent possibility of reduced comfort or disruption to time-dependent household practices $[35,36,58,76]$, as discussed above. For example, EV drivers may be concerned that their vehicle may not be available for use when required [78]. However, the literature shows that this concern is not only about these possible effects, but also and more fundamentally about the loss of a sense of agency and autonomy that is valued in itself [61].

Trust between citizens and project proponents is the crucial threshold in the granting of social license $[14,16,42]$. Users' concerns about loss of control are articulated with reference to a lack of trust in industry, which is a common theme in the research on challenges in DSM $[11,35,55,56,61,75]$ as well as the broader literatures on smart homes [e.g. 79]. Rodden et al. suggest that smart energy systems should be designed to support trust between households and energy providers [75]. As is discussed further in the following section, acceptance of automation for DSM is impeded where householders suspect that it is designed to strengthen utility control behind the meter [80]. Issues of trust may also 
influence which stakeholders are perceived by households as suitable owners of smart systems. Alan et al. found that system ownership mattered to the study participants, who generally preferred independent organizations or governments as system providers [81]. Users have also expressed a lack of trust that technologies themselves will operate as they are supposed to, which arises from reservations about their perceived complexity, unreliability, and potential for malfunction or cybersecurity breaches $[35,49,56,58,61,71,75,76,82-84]$. For example, the perceived complexity of operating smart washing machines compared to regular machines was cited as a reason for discontinuation of use by some householders in a load shifting trial in the Netherlands [85]. Trust is also linked to the perception of risks as many studies view trust to be an explanatory variable for risk perception [e.g. 86]. A literature review of the meaning of trust in risk management points to the importance of distinguishing between relational trust and trust based on the experience of previous behavior [87]. Furthermore, a significant body of research in the SLO literature looks at how organizational relationships that comprise an industry can create trust issues, such as gaps in communication between mining companies and farmers [14,41].

The literature highlights that concerns about loss of control are closely associated with the meaning of home and the sense of privacy and autonomy in the home. Studies exploring perceptions of automation have found that participants widely view it as a potential invasion or intrusion into the private sphere $[22,58,76,78]$, which reflects similar observations in the literature on smart homes and smart meters $[35,79]$. One dimension of this is related to the security and potential misuse of data about what people are doing inside their homes [56,71,78,88]. For this reason, participants of some studies have indicated a preference for the local, semi-automation of smart appliances by householders themselves, rather than DLC, because this is perceived to allow them to retain more control over their data [56].

It is clear that a sense of control or lack of control is highly contingent on the specific context within which householders are presented these programs. Factors such as tenure (e.g. whether householders rent or own their homes) and existing technologies (e.g. whether they are used to district heating or gas central heating) may shape their perspectives on these programs and their automation component. Yilmaz et al. [89] highlighted that the acceptance of the DLC of devices such as heat pumps, PV and batteries was significantly lower for house residents compared to apartment residents. This may be related to the sense of control that the former have as the sole owners of these systems, in contrast to apartment occupants who may, for example, share one heat pump in the whole building. Likewise, Fell et al. [61] found that participants with district heating were more accepting of DLC than those without it because they are accustomed to external control.

Those initiatives that allow less control are more likely to be rejected. Moser [90] noted a significant causal influence of perceived control on the willingness of participants of an online experiment to shift dishwasher use to peak production times, registering a significant drop in willingness if consumers perceived a lack of control. Conversely, where users feel more in control, they may be more inclined to accept and embrace automation in DSM. Different levels of automation in DSM imply different levels of control and therefore elicit different responses from energy users. DLC, which to some degree removes a sense of agency from the user in order to achieve the desired load shifts or peak shaves, trades this agency in for the reduction of cognitive and time-related effort required of users. This is a very delicate matter that needs careful handling and dedicated effort to communicate a sense of control to users if a SLA is to be obtained. The existing research literature identifies some of the conditions in which users feel in control. Fell [91] lists information and 
predictability as among the key antecedents of perceived control. Providing users with a sense of when they can expect what to happen in an automated system, enabling them to form reliable expectations and plan accordingly, is an important factor that contributes to a perception of agency $[39,75,76,92]$.

One of the most crucial conditions for the acceptability of automated DSM for householders is the availability of 'different choices about if and when they would like the system to control their household appliances' [35, p. 92; emphasis in original] [91]. Several studies explore or suggest combining automation with user control, for example through the possibility to revise automation schedules $[93,94]$, or the option to specify preferences for maximum savings or comfort for the day $[95,96]$. When such systems provide users with a feeling of control, some users are also more accepting of temporary discomfort [97] or larger temperature variations at home [73]. The possibility to opt out of automated control at any time with an override option is particularly important to users [12,22,56,64,76,85,98-101]. Overrides may be necessary in exceptional situations, such as when people are ill at home from work or school and the indoor climate becomes more critical [64], or in everyday life when the goals of automated HEMS, such as to maximize self-consumption of rooftop PV-generated power, may clash with household needs, for instance to do laundry not when PVgenerated energy is available but at other times that suit household members [94].

Choice goes beyond the question of opting in or out, however, and requires multiple attractive options that provide relevant benefits [75]. For example, the literature indicates that people are prepared to permit energy companies remote control of their household appliances if they feel they are adequately compensated financially [98] or rewarded with recognition of the role that they play in supporting the electricity grid [35,58]. This last observation points to another issue that influences acceptance of automation for DSM: the extent to which householders understand the rationale for DSM and consider themselves as having a part to play in it. This issue is explored further in the following section.

These findings suggest that people may be open to automation where schemes are implemented in such a way as to preserve a sense of control. Indeed, they may even prefer DLC to other DSM schemes, as some studies have found where participants perceive themselves to be in control of the conditions in which they may choose to cede control over their energy consumption. Buchanan et al. found that focus group participants preferred a DLC scheme to alternative 'community rewards' and 'gamification' proposals [35]. Similarly, Fell et al. found that a DLC scheme was the preferred option for focus group participants who were presented with four variable tariff structures and a DLC option with lower-than-average flat electricity rate [98].

The literature reviewed here indicates that it is important that people feel that they have autonomously consented to the terms of the DSM program. In the same way that procedural fairness is integral to the granting of a social license, the design and roll-out of DLC, in particular, acceptability depends on the option to opt out at any time. This necessity for user control highlights that consent is dynamic, rather than a singular moment of 'obtaining' license. These findings also underline that control is a complex concept, and that it is possible for people to feel in control (in the deeper sense of having chosen to subscribe to a DSM scheme) over the extent to which they are in control (in a narrower sense) of whether their appliances are drawing electricity from the grid at any given time, for example. 


\subsection{From trust to governance and ownership: a stake in the energy system}

The emergence of attempts to institutionalise collective approaches to energy resource creation, such as renewable energy cooperatives [102], point to the importance of governance to the energy transition. Here, the social dimensions of a 'social license' extend from the individual user's relationship with the energy company, to collective arrangements between users in the oversight of organisations. Whilst an unwillingness on the part of users to participate in DSM programs is often associated with a lack of trust, the question of who benefits underlies much skepticism in new energy initiatives, such as automated DSM programs [55,61]. Participants in the research to date have questioned the interests served by DSM. In particular, they have expressed a suspicion that energy companies, acting in their own interests, are the primary or sole beneficiaries $[58,61,75,103]$. They also suspect that energy companies may actually undermine the interests of users, for example by extracting and utilizing household data or by 'influenc[ing] smart appliances to switch on at expensive times which would be difficult to control or detect' [56, p. 36]. For example, in field work carried out in Denmark [104], residents with a rooftop PV installation questioned the reliability of the remote control of their EV once they realized that it was not charged according to the PV electricity generation and they ended up paying extra money. Concerns about data sharing and privacy are voiced far less with respect to community-based models of DSM in comparison [60]; similarly people prefer state institutions to service operators for IoT-based demand response [105]. This implies that mistrust arises less from what is required of users or what kind of technologies are involved, than from what kinds of actors are involved and the relationships between them. For example, Rodden et al. [75] observe that the privacy concerns of participants were related not to availability of their data per se but to how utilities might exploit that data.

Organizational form - whether public or privately owned - and its governance is a crucial determinant of user willingness to cede control over devices in large part because of the multiple possible uses of that data. The literature suggests that users may reject proposals to employ automation for DSM when they do not understand or accept the necessity of DSM broadly or the use of automation technologies to achieve it. The mistrust in energy companies arises in part from the multiple and diverse functions that DSM is said to achieve, where for example 'People recognised a misalignment between their own ends (e.g. energy services) and those of energy companies (e.g. profit) being sought through the same means' [61, p. 1125]. Participants in several studies have raised questions about how the purported objectives of environmental sustainability and reduced energy consumption could be achieved through DSM schemes that are run by companies with an interest in increased energy consumption $[35,55]$, or that typically shift consumption from one time to another rather than reducing it [103], or that depend on technologies such as smart meters that themselves use energy [56]. While the various ends of the smart grid arguably can and will coexist, these findings show that mistrust can come about when people discern from these mixed and competing narratives the potential to be misled and exploited - indeed, there is also evidence suggesting that this 'sense of the consumer being misled may be the smart grid's real Achilles heel' [103, p. 163].

Insofar as new DSM programs represent a form of innovation whose proponents aim to be 'responsible' in the eyes of citizens, knowledge of who owns these programs, benefits from them and will be responsible if things go wrong are key determinants of the overall success of automated DSM $[106,107]$. Studies have observed that participants were 'keen to establish where the initiative was coming from' [35, p. 94] and that 'they need to know and respect the reasoning behind [it]' [76, p. 
2330; emphasis added]. Clarity about what energy companies and householders may get out of DSM can be a decisive factor in acceptance of DSM. Buchanan et al. [35, p. 95], comparing participants' responses to different models in the study described above, argue that automation could have been the favored model because 'the contract between energy providers and consumers may have been easier for people to comprehend and thus trust'. The participants were receptive to an arrangement, freely and transparently entered, in which they received reduced energy bills in exchange for enabling energy companies to reduce strain on the grid through DLC. Transparency concerning not only the rationale for programs but prospective beneficiaries is therefore one crucial determinant of a SLA.

Governance of wider energy assets at the edge of grids - remote towns, those at the end of long transmission lines, or islands with unreliable energy connections - crucially shapes receptiveness to participate in automated DSM programs. Users form reasons for wishing to engage in DSM that speak to their situated experiences and go beyond adequate compensation for contributing to an initiative that they understand and approve of. Users' direct experiences of energy issues in diverse contexts can generate what Skjølsvold et al. [108] refer to as a 'grid sensitivity'. Based on their experiences of a weak grid connection to the mainland, island inhabitants may be motivated by energy security concerns more than by climate change and sustainability, for example. Grid sensitivity can form the basis of both practical and political engagement with the electricity grid, and the 'desires and visions' of grid-sensitive communities may potentially be 'well-aligned with the goals of actors who promote smart energy visions', even if for different reasons [108, p. 7, 109]. This suggests that anchoring DSM initiatives in the actual worlds and concerns of users [110,111] and 'seriously engaging society based on place specific issues [...] is likely to increase the chances of success' [108, p. 8].

The idea that DSM is necessary to maintain the electricity grid in the interests of all stakeholders may have resonance with energy users. It has been observed that people may be more engaged where there is a sense of 'being part of something' bigger [58,62,103,112, p. 184]. Indeed, based on a field work, Nyborg and Røpke [113] observed different profiles whose motivations in engaging in automated DSM initiatives included 'contribution to technological and societal development, as well as doing something good for others for the sake of the environment and greater cause'. According to Goulden et al. [55], such a sense of a co-ownership - which they argue is associated with a model of the 'energy citizen' rather than the 'energy consumer' - accounts for the popularity of community energy schemes in stark contrast with pervasive distrust of major UK energy suppliers. This is consistent with the observation in a study in the Netherlands that "rather than an outright antipathy towards service providers and striving for radical autonomy, participants were looking for "a new balance" that allows for more decentralised and democratic control' [60, p. 132] and for publics playing more active roles than being reduced to mere consumers [103]. The concept of energy citizenship has been mobilized to describe how people can become more aware and play more active roles [114,115]. This is essential for the success of automated DSM programs because, as described above, a SLA is not won by merely transferring information to passive recipients, but by inviting them to take an active part in a different mode of energy management.

Ryghaug et al. [115] suggest the need to move beyond the notion of 'public acceptance' that has dominated attempts to achieve public support for energy transitions. In this approach, energy users have figured predominantly as 'imagined threats that can disapprove and protest' [109, p. 93] in ways analogous to the communities in studies of SLO in mining [42]. However, as argued by Ryghaug et al., 'the potential agency of diverse publics moves far beyond the accept/reject dichotomy' [115, $\mathrm{p}$. 284]. Scholars in the energy social sciences have called for this agency of energy users to be taken 
seriously, for example by re-conceptualizing DSM as co-management [116]. It would involve the engagement of energy users not only following technology and program design, but from the beginning [111] and in such a way as to incorporate users' perceptions of the key problem to be addressed and their suggested solutions [109]. Thus, we see that trust in automation or the SLA should not be considered a matter of a relationship that first and foremost concerns how individuals relate to technologies, but of how communities engage with the issues affecting them, not just individually but collectively - as well as how new communities can form around issues and the technologies designed to address them [117]. Domestic energy consumption is, as Hargreaves et al [118, p. 6118] point out, 'a social and collective rather than individualised process'. Thus, in line with newer ideas about how to change demand, we see that re-conceptualizing DSM as co-management, and broadening the scope of interventions to also target a much wider repertoire of actors and technologies that shape energy practices $[102,116,119]$, is necessary. This underscores that political participation is not limited to agreement about DSM, but that participation in DSM itself is a form of material politics [120]. In fact, drawing on concepts from the SLO literature may be useful as it serves to highlight the community aspects of resource management, more so than traditional DSM and smart grids proponents have managed to do - as they have traditionally focused on individual consumers and cast flexibility loads and user flexibility as individual resources to managed by companies or third parties.

\section{Conclusion}

This paper has provided a critical 'narrative review' of the prospects for a 'social license to automate' demand-side management. We have charted three themes where the concept of a 'social license' adapted from the mining and resource extraction literature serves as a sensitizing concept to help to illuminate emergent issues with the resource of electricity user flexibility. We have established that public resistance to automation in DSM programs has centred on 1) the requirement to change energy practices to facilitate load flexibility without consideration of the differential flexibility capacity held by households; 2) the agency and sense of control on the part of the user in participating in these programs; and 3) the extent to which users not only perceive DSM to be aligned with their interests but are also substantively involved in sharing its benefits. These (mis)alignments represent areas in which the expectations embedded within models of automation in DSM by various policy and industry proponents can be at odds with users' expectations and aspirations. More specifically, we show that these models may not have sufficiently taken into account the extent to which the success of DSM depends upon the active participation and buy-in of users - but also that their engagement can take different forms than those often anticipated by program designers. Crucially, this misalignment is because flexibility is both a resource to be capitalized upon by new businesses and technologies and consists in the capacity of users to contribute to grid stability.

The first area of misalignment of expectations concerns the social practices that shape load flexibility available for automation. Our literature review suggests that the expectation that automation can achieve flexibility 'behind the scenes' overlooks the extent to which it also requires of users a new kind of flexibility, assuming them to be unbothered by the alteration to household energy practices, undesirable indirect effects, and additional 'flexibility labor' that automated DSM can bring. The literature demonstrates flexibility capital, or the ability to shift energy use in time and space [66], is a highly unevenly distributed capacity among different groups of energy users at different times. This inequity means that automated DSM has the potential to deepen existing energy injustices in ways that privilege the already privileged [121]. Thus, we clearly see the importance of not only focusing 
on those who may choose whether or not to grant a license to different automation programs, but also to those who may be unable to participate but are nevertheless affected.

Typically industry and market actors frame the capacity of users to provide flexibility as a resource. The concept of a 'social license' has the potential to make this framing more explicit through quantifying user automation and their opinions and concerns about it. On the other hand, we have seen that flexibility also may be regarded as a capacity. Whether we see flexibility capital to be considered a capability [122] or a resource may have interesting implications for energy justice discussions [123], to be explored in future research. Consequently, what stands clear is the need in $\mathrm{t}$ to broaden the original SLO scope beyond the extension of markets and technology to attend to questions of who is included and who is excluded, and who wins and who loses, in automated DSM; namely those who are unable to shift energy usage patterns, those with more or less flexible working hours and caring commitments, and with more resources to aid in load shifting. By accounting for capacities of different DSM users with a democratic view of stakeholders in DSM, the methods associated with a 'social license' can help to calibrate such discussions of equity.

Second, there is no simple boundary between user perceptions and experiences of the grid and the resource of flexibility. 'Grid sensitivity' - the accumulated experiences of pivotal events such as service disruption that shape expectations about the energy sector - underpins a collective consciousness that shapes how DSM projects will be received. The literature on users' responses to automated DSM indicates that a sense of control is highly important, and users' requirements for a sense of control may not simply be satisfied or offset by financial compensation or other measures. However, the literature suggests that the forms and degrees of active and passive interaction involved in various levels of automated DSM do not correspond neatly or predictably with the sense of control that people perceive. Relatively 'passive' engagement through DLC, for example, is not necessarily inconsistent with a sense of autonomy with respect to the terms on which a household has opted to enter the program. The results of our investigation point to a need for more attention to the conditions in which people perceive a sense of autonomy and corresponding considerations in DSM program and technology designs. This problem of perceived autonomy versus inconvenience or harm mirrors the mining social license continuum along which stakeholder perceptions of a project are graded. Social license is thus contextual, multifaceted and contingent.

Third, conflicting interests between program proponents in DSM programs and the various stakeholder groups of users, electricity companies, system operators and other actors are likely to lead to unanticipated consequences that will affect the technology's development. The social license literature has much to offer here, including sociological insights on 'structural holes' between farmers and miners that may emerge both through competition between firms and characteristics of their organizational structures [14, p. 114]. This literature sensitizes us to the ways that the acceptance of automated DSM depends on users' knowledge of why the program is being implemented and how all the actors involved - including themselves - may benefit. To understand how a SLA might be achieved, we also need to attend to how individuals may be engaged more collectively, as energy citizens or energy communities, and how more collective routes to participation in automated DSM initiatives may be nurtured, maintained or dispersed - again a reflection of the original SLO literature examining how issues affect groups.

Understanding the potential for DSM to create both winners and losers will be vital to this collective engagement. People may be open to subscribing to various models of automation in DSM and may 
even do so for a variety of reasons or in exchange for different forms of compensation (whether financial, community, etc) - all provided that they know what they are signing up for and why. Furthermore, certain groups and types of energy use may also be effectively punished more than others in order to obtain flexibility. Dedicated future research on collective approaches to automation to address such prevailing challenges would be highly beneficial for technology developers, policy managers, energy system managers and citizens.

Our critical review has proposed a SLA in order to better conceptualize automated DSM 'solutions' as emerging socio-technological systems in need of public deliberation. We have outlined key touchpoints where the original concept translates well and contributes to a broadening of thought regarding the acceptance of automated DSM, sensitizing our analysis towards often overlooked aspects and lending a more comprehensive and multi-lensed perspective. The analysis has further allowed us to identify components of the traditional social license concept that would profit from augmentation by important aspects that are brought to light by a socio-technical systems perspective. These aspects, according to Miller et al. [124, p. 136], 'include the social processes that stimulate and manage energy transformation, the social changes that accompany shifts in energy technologies, and the social outcomes that flow from the organization and operation of novel energy systems' and ultimately raise questions of 'Who will benefit from new energy systems, who will lose, and whose lives and livelihoods will be put at risk?'. These deeper issues of risk, trust, benefit and access lie at the core of the prospects for a social license to automate, as this review of the literature has shown.

This review has largely excluded issues at the intersection between the SLA, public engagement, user diversity, energy justice, and energy citizenship, instead focusing on empirical research on the household sector. These pressing issues we contend are too important to be superficially dealt with in this review, but deserve their own literature review. Public engagement and energy citizenship is a fast-emerging research field, which denotes citizens' participation rather than their mere acceptance. Our review touches on this area $[115,119]$, but a separate review would highlight more research, especially in the area of automation relating to energy citizens communities and micro-grids, e.g. [125]. Whereas public engagement and energy citizenship go hand in hand, energy justice links more to issues related to the exclusion of vulnerable groups through complex technology, automation and energy use, which have recently been studied [by e.g. 126-128].

We would suggest that research tools and perspectives built by a social license research are compatible with concerns of justice, engagement and citizenship in automated systems. Where market-based governance of electricity systems prevail, this is especially true, as the tools of social license research have been built in situations where competitive pressures push corporate decisionmakers to manage, quantify and ultimately exclude social concerns [15,16,44].

We have stressed that the concept of a social license is, like many boundary concepts [102], powerful in its malleability: it attempts to hold together the various and variable groups affected by resource projects that are increasingly diffuse and dispersed as climate change connects different communities of concern. It also speaks to the limits of the regulatory state and the granting of formal procedural legal licenses in the development of new resources projects $[14,41,44]$. We have attempted to keep in play the tensions of the concept of a social license in considering its applicability to the domain of DSM. Social license is both a managerial device for project proponents to negotiate the terms of a project and a concept for social license researchers to evaluate mining projects and industrial players 
according to liberal norms of fairness, equity, and procedural justice. It is thus both a vehicle for, and avenue to make accountable, the power of project developers. Therefore, based on this review, we suggest amending the social license concept in the context of DSM by attending to who dominates participation discourse and making room for the voices of affected actors, allowing for a more integrative, collaborative and just approach [c.f. 14]. We believe that reframed in this way, the social license concept has the potential to serve researchers and citizens well in aiming to understand how DSM projects enable and constrain democratic participation in energy systems.

\section{References}

[1] European Commission, SET-Plan ACTION n³.2 Implementation Plan: Europe to become a global role model in integrated, innovative solutions for the planning, deployment, and replication of Positive Energy Districts, (2018).

https://setis.ec.europa.eu/system/files/setplan_smartcities_implementationplan.pdf.

[2] R.G. Boutilier, From metaphor to political spin: Understanding criticisms of the social licence, Extr. Ind. Soc. (2020). https://doi.org/10.1016/j.exis.2020.05.022.

[3] E. Hillberg, A. Zegers, B. Herndler, S. Wong, J. Pompee, J.-Y. Bourmaud, S. Lehnhoff, G. Migliavacca, K. Uhlen, I. Oleinikova, H. Pihl, M. Norström, M. Persson, J. Rossi, G. Beccuti, Flexibility needs in the future power system, (n.d.) 48.

[4] P. Grünewald, M. Diakonova, Flexibility, dynamism and diversity in energy supply and demand: A critical review, Energy Res. Soc. Sci. 38 (2018) 58-66. https://doi.org/10.1016/j.erss.2018.01.014.

[5] C. Mitchell, Momentum is increasing towards a flexible electricity system based on renewables, Nat. Energy. 1 (2016) 1-6. https://doi.org/10.1038/nenergy.2015.30.

[6] G.Y. Lee, B.S. Ko, J.S. Lee, R.Y. Kim, An off-line design methodology of droop control for multiple bi-directional distributed energy resources based on voltage sensitivity analysis in DC microgrids, in: 2020.

[7] M.S.H. Nizami, M.J. Hossain, B.M.R. Amin, E. Fernandez, A residential energy management system with bi-level optimization-based bidding strategy for day-ahead bi-directional electricity trading, Appl. Energy. 261 (2020) 114322. https://doi.org/10.1016/j.apenergy.2019.114322.

[8] W. van Westering, H. Hellendoorn, Low voltage power grid congestion reduction using a community battery: Design principles, control and experimental validation, Int. J. Electr. Power Energy Syst. 114 (2020) 105349. https://doi.org/10.1016/j.ijepes.2019.06.007.

[9] G. Tévar, A. Gómez-Expósito, A. Arcos-Vargas, M. Rodríguez-Montañés, Influence of rooftop PV generation on net demand, losses and network congestions: A case study, Int. J. Electr. Power Energy Syst. 106 (2019) 68-86. https://doi.org/10.1016/j.ijepes.2018.09.013.

[10] F. Muniesa, M. Callon, Economic experiments and the construction of markets, in: Econ. Make Mark. Performativity Econ., Princeton University Press, 2008.

[11] K. Stenner, E.R. Frederiks, E.V. Hobman, S. Cook, Willingness to participate in direct load control: The role of consumer distrust, Appl. Energy. 189 (2017) 76-88. https://doi.org/10.1016/j.apenergy.2016.10.099.

[12] X. Xu, C. Chen, X. Zhu, Q. Hu, Promoting acceptance of direct load control programs in the United States: Financial incentive versus control option, Energy. 147 (2018) 1278-1287. https://doi.org/10.1016/j.energy.2018.01.028. 
[13] K. Kama, M. Kuchler, Geo-Metrics and Geo-Politics: Controversies in Estimating European Shale Gas Resources, in: A. Bobbette, A. Donovan (Eds.), Polit. Geol. Act. Stratigr. Mak. Life, Springer International Publishing, Cham, 2019: pp. 105-145. https://doi.org/10.1007/978-3-319-98189-5_4.

[14] R.G. Boutilier, I. Thomson, The Social License: The Story of the San Christobel Mine, Routledge, Abingdon, UK, 2018.

[15] M. Brueckner, M. Eabrasu, Pinning down the social license to operate (SLO): The problem of normative complexity, Resour. Policy. 59 (2018) 217-226.

https://doi.org/10.1016/j.resourpol.2018.07.004.

[16] D.D. Kuch, D.G. Ellem, D.M. Bahnisch, S. Webb, Social License and Communications Report, Centre for Research in Energy and Resources, University of Newcastle. Report for the Australian Council of Learned Academies, Securing Australia's Future: Project Six Engineering Energy: Unconventional Gas Production, 2013.

[17] H. Blumer, What is Wrong with Social Theory?, Am. Sociol. Rev. 19 (1954) 3-10.

[18] J. Rinkinen, E. Shove, G. Marsden, Conceptualising Demand: A Distinctive Approach to Consumption and Practice, 2020. https://www.routledge.com/Conceptualising-Demand-ADistinctive-Approach-to-Consumption-and-Practice/Rinkinen-ShoveMarsden/p/book/9780367465025 (accessed December 18, 2020).

[19] I.F. Ballo, Imagining energy futures: Sociotechnical imaginaries of the future Smart Grid in Norway, Energy Res. Soc. Sci. 9 (2015) 9-20. https://doi.org/10.1016/j.erss.2015.08.015.

[20] W. Throndsen, What do experts talk about when they talk about users? Expectations and imagined users in the smart grid, Energy Effic. 10 (2017) 283-297. https://doi.org/10.1007/s12053-0169456-5.

[21] L. Schick, C. Gad, Flexible and inflexible energy engagements-A study of the Danish Smart Grid Strategy, Energy Res. Soc. Sci. 9 (2015) 51-59. https://doi.org/10.1016/j.erss.2015.08.013.

[22] R. Smale, B. van Vliet, G. Spaargaren, When social practices meet smart grids: Flexibility, grid management, and domestic consumption in The Netherlands, Energy Res. Soc. Sci. 34 (2017) 132140. https://doi.org/10.1016/j.erss.2017.06.037.

[23] H. Bulkeley, G. Powells, S. Bell, Smart grids and the constitution of solar electricity conduct, (2016). https://journals.sagepub.com/doi/10.1177/0308518X15596748 (accessed December 17, 2020).

[24] E. Shove, N. Cass, Time, Practices and Energy Demand: implications for flexibility, (n.d.) 14.

[25] C.P. Janssen, S.F. Donker, D.P. Brumby, A.L. Kun, History and future of human-automation interaction, Int. J. Hum.-Comput. Stud. 131 (2019) 99-107.

https://doi.org/10.1016/j.ijhcs.2019.05.006.

[26] S. Karjalainen, Should it be automatic or manual-The occupant's perspective on the design of domestic control systems, Energy Build. 65 (2013) 119-126.

https://doi.org/10.1016/j.enbuild.2013.05.043.

[27] T.B. Sheridan, W.L. Verplank, Human and Computer Control of Undersea Teleoperators, MIT, Cambridge, MA, 1978.

[28] K.L. van den Broek, I. Walker, C.A. Klöckner, Drivers of energy saving behaviour: The relative influence of intentional, normative, situational and habitual processes, Energy Policy. 132 (2019) 811-819. https://doi.org/10.1016/j.enpol.2019.06.048. 
[29] M. Goulden, A. Spence, J. Wardman, C. Leygue, Differentiating 'the user' in DSR: Developing demand side response in advanced economies, Energy Policy. 122 (2018) 176-185. https://doi.org/10.1016/j.enpol.2018.07.013.

[30] P. Cappers, A. Mills, C. Goldman, R. Wiser, J.H. Eto, An assessment of the role mass market demand response could play in contributing to the management of variable generation integration issues, Energy Policy. 48 (2012) 420-429. https://doi.org/10.1016/j.enpol.2012.05.040.

[31] J. Stromback, C. Dromacque, M.H. Yassin, The potential of smart meter enabled programs to increase energy and systems efficiency: a mass pilot comparison Short name: Empower Demand, (2011) 92.

[32] B. Parrish, R. Gross, P. Heptonstall, On demand: Can demand response live up to expectations in managing electricity systems?, Energy Res. Soc. Sci. 51 (2019) 107-118.

https://doi.org/10.1016/j.erss.2018.11.018.

[33] C. Cuijpers, B.-J. Koops, Smart Metering and Privacy in Europe: Lessons from the Dutch Case, in: S. Gutwirth, R. Leenes, P. de Hert, Y. Poullet (Eds.), Eur. Data Prot. Coming Age, Springer Netherlands, Dordrecht, 2013: pp. 269-293. https://doi.org/10.1007/978-94-007-5170-5_12.

[34] T. von Wirth, L. Gislason, R. Seidl, Distributed energy systems on a neighbourhood scale: Reviewing drivers of and barriers to social acceptance, Renew. Sustain. Energy Rev. 82 (2018) $2618-2628$.

[35] K. Buchanan, N. Banks, I. Preston, R. Russo, The British public's perception of the UK smart metering initiative: Threats and opportunities, Energy Policy. 91 (2016) 87-97. https://doi.org/10.1016/j.enpol.2016.01.003.

[36] W. Mert, J. Suschek-Berger, W. Tritthart, Consumer acceptance of smart appliances, Intelligent Energy Europe, 2008.

[37] T. Hargreaves, Governing Energy Use at Home: Smart Meters, Governmentality and Resistance, Norwich, 2012. https://3 sresearch.org/2014/12/04/hargreaves-2012-01-smart-meters/.

[38] N. Balta-Ozkan, O. Amerighi, B. Boteler, A comparison of consumer perceptions towards smart homes in the UK, Germany and Italy: reflections for policy and future research, Technol. Anal. Strateg. Manag. 26 (2014) 1176-1195. https://doi.org/10.1080/09537325.2014.975788.

[39] P. Fröhlich, M. Baldauf, T. Meneweger, M. Tscheligi, B. de Ruyter, F. Paterno, Everyday automation experience: a research agenda, Pers. Ubiquitous Comput. 24 (2020) 725-734.

[40] M. Ryghaug, T.M. Skjølsvold, Pilot Society and the Energy Transition: The co-shaping of innovation, participation and politics, Palgrave Pivot, 2021. https://www.palgrave.com/gp/book/9783030611835 (accessed December 18, 2020).

[41] R.G. Boutilier, Frequently asked questions about the social licence to operate, Impact Assess. Proj. Apprais. 32 (2014) 263-272. https://doi.org/10.1080/14615517.2014.941141.

[42] K. Moffat, J. Lacey, A. Zhang, S. Leipold, The social licence to operate: a critical review, Forestry. 89 (2016) 477-488. https://doi.org/10.1093/forestry/cpv044.

[43] N.L. Hall, Can the "Social Licence to Operate" Concept Enhance Engagement and Increase Acceptance of Renewable Energy? A Case Study of Wind Farms in Australia, Soc. Epistemol. 28 (2014) 219-238. https://doi.org/10.1080/02691728.2014.922636.

[44] J.R. Owen, Social license and the fear of Mineras Interruptus, Geoforum. 77 (2016) 102-105. https://doi.org/10.1016/j.geoforum.2016.10.014. 
[45] S. Bice, What Gives You a Social Licence? An Exploration of the Social Licence to Operate in the Australian Mining Industry, Resources. 3 (2014) 62-80. https://doi.org/10.3390/resources3010062.

[46] J. Kester, Governing electric vehicles: mobilizing electricity to secure automobility, Mobilities. 13 (2018) 200-215. https://doi.org/10.1080/17450101.2017.1408984.

[47] B.K. Sovacool, J. Axsen, S. Sorrell, Promoting novelty, rigor, and style in energy social science: Towards codes of practice for appropriate methods and research design, Energy Res. Soc. Sci. 45 (2018) 12-42. https://doi.org/10.1016/j.erss.2018.07.007.

[48] Y. Strengers, Smart energy in everyday life: are you designing for resource man?, Interactions. 21 (2014) 24-31. https://doi.org/10.1145/2621931.

[49] N. Verkade, J. Höffken, Is the Resource Man coming home? Engaging with an energy monitoring platform to foster flexible energy consumption in the Netherlands, Energy Res. Soc. Sci. 27 (2017) 36-44. https://doi.org/10.1016/j.erss.2017.02.015.

[50] T. Pallesen, R.P. Jenle, Organizing consumers for a decarbonized electricity system: Calculative agencies and user scripts in a Danish demonstration project, Energy Res. Soc. Sci. 38 (2018) 102109. https://doi.org/10.1016/j.erss.2018.02.003.

[51] G. Powells, H. Bulkeley, S. Bell, E. Judson, Peak electricity demand and the flexibility of everyday life, Geoforum. 55 (2014) 43-52. https://doi.org/10.1016/j.geoforum.2014.04.014.

[52] T.H. Christensen, F. Friis, Materiality and automation of household practices: Experiences from a Danish time shifting trial, (n.d.) 11.

[53] Y. Strengers, Negotiating everyday life: The role of energy and water consumption feedback, J. Consum. Cult. 11 (2011) 319-338. https://doi.org/10.1177/1469540511417994.

[54] E. Shove, G. Walker, What Is Energy For? Social Practice and Energy Demand, Theory Cult. Soc. 31 (2014) 41-58. https://doi.org/10.1177/0263276414536746.

[55] M. Goulden, B. Bedwell, S. Rennick-Egglestone, T. Rodden, A. Spence, Smart grids, smart users? The role of the user in demand side management, Energy Res. Soc. Sci. 2 (2014) 21-29. https://doi.org/10.1016/j.erss.2014.04.008.

[56] A.-G. Paetz, E. Dütschke, W. Fichtner, Smart Homes as a Means to Sustainable Energy Consumption: A Study of Consumer Perceptions, J. Consum. Policy. 35 (2012) 23-41. https://doi.org/10.1007/s10603-011-9177-2.

[57] A. Spence, C. Demski, C. Butler, K. Parkhill, N. Pidgeon, Public perceptions of demand-side management and a smarter energy future, Nat. Clim. Change. 5 (2015) 550-554. https://doi.org/10.1038/nclimate2610.

[58] N. Murtagh, B. Gatersleben, D. Uzzell, A qualitative study of perspectives on household and societal impacts of demand response, Technol. Anal. Strateg. Manag. 26 (2014) 1131-1143. https://doi.org/10.1080/09537325.2014.974529.

[59] F. Friis, T.H. Christensen, The challenge of time shifting energy demand practices: Insights from Denmark, Energy Res. Soc. Sci. 19 (2016) 124-133. https://doi.org/10.1016/j.erss.2016.05.017.

[60] J. Naus, B.J.M. van Vliet, A. Hendriksen, Households as change agents in a Dutch smart energy transition: On power, privacy and participation, Energy Res. Soc. Sci. 9 (2015) 125-136. https://doi.org/10.1016/j.erss.2015.08.025. 
[61] M.J. Fell, D. Shipworth, G.M. Huebner, C.A. Elwell, Exploring perceived control in domestic electricity demand-side response, Technol. Anal. Strateg. Manag. 26 (2014) 1118-1130. https://doi.org/10.1080/09537325.2014.974530.

[62] M. Hansen, B. Hauge, Prosumers and smart grid technologies in Denmark: developing user competences in smart grid households, Energy Effic. 10 (2017) 1215-1234.

https://doi.org/10.1007/s12053-017-9514-7.

[63] Y. Strengers, Air-conditioning Australian households: The impact of dynamic peak pricing, Energy Policy. 38 (2010) 7312-7322. https://doi.org/10.1016/j.enpol.2010.08.006.

[64] V. Sugarman, E. Lank, Designing Persuasive Technology to Manage Peak Electricity Demand in Ontario Homes, in: Proc. 33rd Annu. ACM Conf. Hum. Factors Comput. Syst., Association for Computing Machinery, New York, NY, USA, 2015: pp. 1975-1984. https://doi.org/10.1145/2702123.2702364.

[65] M. Kubli, M. Loock, R. Wüstenhagen, The flexible prosumer: Measuring the willingness to cocreate distributed flexibility, Energy Policy. 114 (2018) 540-548. https://doi.org/10.1016/j.enpol.2017.12.044.

[66] G. Powells, M.J. Fell, Flexibility capital and flexibility justice in smart energy systems, Energy Res. Soc. Sci. 54 (2019) 56-59. https://doi.org/10.1016/j.erss.2019.03.015.

[67] L. Michaels, Y. Parag, Motivations and barriers to integrating 'prosuming' services into the future decentralized electricity grid: Findings from Israel, Energy Res. Soc. Sci. 21 (2016) 70-83. https://doi.org/10.1016/j.erss.2016.06.023.

[68] J. Crawley, C. Johnson, P. Calver, M. Fell, Demand response beyond the numbers: A critical reappraisal of flexibility in two United Kingdom field trials, Energy Res. Soc. Sci. 75 (2021) 102032. https://doi.org/10.1016/j.erss.2021.102032.

[69] C. Johnson, Is demand side response a woman's work? Domestic labour and electricity shifting in low income homes in the United Kingdom, Energy Res. Soc. Sci. 68 (2020) 101558. https://doi.org/10.1016/j.erss.2020.101558.

[70] L. Tjørring, C.L. Jensen, L.G. Hansen, L.M. Andersen, Increasing the flexibility of electricity consumption in private households: Does gender matter?, Energy Policy. 118 (2018) 9-18. https://doi.org/10.1016/j.enpol.2018.03.006.

[71] R. Lackes, M. Siepermann, G. Vetter, Turn it on! - User acceptance of direct load control and load shifting of home appliances, in: 2018.

[72] S. Nyborg, Pilot Users and Their Families: Inventing Flexible Practices in the Smart Grid, Sci. Technol. Stud. 28 (2015) 54-80. https://doi.org/10.23987/sts.55342.

[73] S. Hagejärd, G. Dokter, U. Rahe, P. Femenías, My apartment is cold! Household perceptions of indoor climate and demand-side management in Sweden, Energy Res. Soc. Sci. 73 (2021) 101948. https://doi.org/10.1016/j.erss.2021.101948.

[74] K. van den Broek, J.W. Bolderdijk, L. Steg, Individual differences in values determine the relative persuasiveness of biospheric, economic and combined appeals, J. Environ. Psychol. 53 (2017) 145-156. https://doi.org/10.1016/j.jenvp.2017.07.009.

[75] T.A. Rodden, J.E. Fischer, N. Pantidi, K. Bachour, S. Moran, At home with agents: exploring attitudes towards future smart energy infrastructures, in: Proc. SIGCHI Conf. Hum. Factors 
Comput. Syst. - CHI 13, ACM Press, Paris, France, 2013: p. 1173. https://doi.org/10.1145/2470654.2466152.

[76] S.J. Darby, I. Pisica, Focus on electricity tariffs: experience and exploration of different charging schemes, in: ECEEE Summer Study Proc., n.d.: p. 11.

[78] J. Bailey, J. Axsen, Anticipating PEV buyers' acceptance of utility controlled charging, Transp. Res. Part Policy Pract. 82 (2015) 29-46. https://doi.org/10.1016/j.tra.2015.09.004.

[79] N. Balta-Ozkan, R. Davidson, M. Bicket, L. Whitmarsh, Social barriers to the adoption of smart homes, Energy Policy. 63 (2013) 363-374. https://doi.org/10.1016/j.enpol.2013.08.043.

[80] J. Naus, G. Spaargaren, B.J.M. van Vliet, H.M. van der Horst, Smart grids, information flows and emerging domestic energy practices, Energy Policy. 68 (2014) 436-446. https://doi.org/10.1016/j.enpol.2014.01.038.

[81] A.T. Alan, E. Costanza, S.D. Ramchurn, J. Fischer, T. Rodden, N.R. Jennings, Tariff Agent: Interacting with a Future Smart Energy System at Home, ACM Trans. Comput.-Hum. Interact. 23 (2016) 25:1-25:28. https://doi.org/10.1145/2943770.

[82] E. Park, S. Kim, Y. Kim, S.J. Kwon, Smart home services as the next mainstream of the ICT industry: determinants of the adoption of smart home services, Univers. Access Inf. Soc. 17 (2018) 175-190. https://doi.org/10.1007/s10209-017-0533-0.

[83] Y. Parag, G. Butbul, Flexiwatts and seamless technology: Public perceptions of demand flexibility through smart home technology, Energy Res. Soc. Sci. 39 (2018) 177-191. https://doi.org/10.1016/j.erss.2017.10.012.

[84] C. Chen, X. Xu, J. Adams, J. Brannon, F. Li, A. Walzem, When East meets West: Understanding residents' home energy management system adoption intention and willingness to pay in Japan and the United States, Energy Res. Soc. Sci. 69 (2020) 101616. https://doi.org/10.1016/j.erss.2020.101616.

[85] C.B.A. Kobus, R. Mugge, J.P.L. Schoormans, Washing when the sun is shining! How users interact with a household energy management system, Ergonomics. 56 (2013) 451-462. https://doi.org/10.1080/00140139.2012.721522.

[86] M. Siegrist, Trust and Risk Perception: A Critical Review of the Literature, Risk Anal. n/a (n.d.). https://doi.org/10.1111/risa.13325.

[87] T.C. Earle, Trust in Risk Management: A Model-Based Review of Empirical Research, Risk Anal. 30 (2010) 541-574. https://doi.org/10.1111/j.1539-6924.2010.01398.x.

[88] H. Yang, H. Lee, H. Zo, User acceptance of smart home services: an extension of the theory of planned behavior, Ind. Manag. Data Syst. 117 (2017) 68-89. https://doi.org/10.1108/IMDS-012016-0017.

[89] S. Yilmaz, X. Xu, D. Cabrera, C. Chanez, P. Cuony, M.K. Patel, Analysis of demand-side response preferences regarding electricity tariffs and direct load control: Key findings from a Swiss survey, Energy. 212 (2020) 118712. https://doi.org/10.1016/j.energy.2020.118712.

[90] C. Moser, The role of perceived control over appliances in the acceptance of electricity loadshifting programmes, Energy Effic. 10 (2017) 1115-1127. https://doi.org/10.1007/s12053-0179508-5.

[91] M.J. Fell, Taking charge: perceived control and acceptability of domestic demand-side response, $\mathrm{PhD}, \mathrm{UCL}, 2016$. 
https://pdfs.semanticscholar.org/4fe8/7ef6d13c76208ed0cb1de1a8a56b2548096c.pdf (accessed July 27, 2020).

[92] X.J. Yang, V.V. Unhelkar, K. Li, J.A. Shah, Evaluating Effects of User Experience and System Transparency on Trust in Automation, in: Proc. 2017 ACMIEEE Int. Conf. Hum.-Robot Interact., Association for Computing Machinery, New York, NY, USA, 2017: pp. 408-416. https://doi.org/10.1145/2909824.3020230.

[93] A.T. Alan, M. Shann, E. Costanza, S.D. Ramchurn, S. Seuken, It is too Hot: An In-Situ Study of Three Designs for Heating, in: Proc. 2016 CHI Conf. Hum. Factors Comput. Syst., Association for Computing Machinery, New York, NY, USA, 2016: pp. 5262-5273. https://doi.org/10.1145/2858036.2858222.

[94] J. Bourgeois, J. van der Linden, G. Kortuem, B.A. Price, C. Rimmer, Conversations with my washing machine: an in-the-wild study of demand shifting with self-generated energy, in: Proc. 2014 ACM Int. Jt. Conf. Pervasive Ubiquitous Comput., Association for Computing Machinery, New York, NY, USA, 2014: pp. 459-470. https://doi.org/10.1145/2632048.2632106.

[95] M. Jain, A. Singh, V. Chandan, Portable+: A Ubiquitous And Smart Way Towards Comfortable Energy Savings, Proc. ACM Interact. Mob. Wearable Ubiquitous Technol. 1 (2017) 14:1-14:22. https://doi.org/10.1145/3090079.

[96] P.A. Aloise-Young, S. Lurbe, S. Isley, R. Kadavil, S. Suryanarayanan, D. Christensen, Dirty dishes or dirty laundry? Comparing two methods for quantifying American consumers' preferences for load management in a smart home, Energy Res. Soc. Sci. 71 (2021) 101781. https://doi.org/10.1016/j.erss.2020.101781.

[97] A. Clear, A. Friday, M. Hazas, C. Lord, Catch my drift? achieving comfort more sustainably in conventionally heated buildings, in: Proc. 2014 Conf. Des. Interact. Syst., Association for Computing Machinery, New York, NY, USA, 2014: pp. 1015-1024. https://doi.org/10.1145/2598510.2598529.

[98] M.J. Fell, D. Shipworth, G.M. Huebner, C.A. Elwell, Public acceptability of domestic demand-side response in Great Britain: The role of automation and direct load control, Energy Res. Soc. Sci. 9 (2015) 72-84. https://doi.org/10.1016/j.erss.2015.08.023.

[99] K. Parkhill, C. Demski, C. Butler, A. Spence, N. Pidgeon, Transforming the UK Energy System: Public Values, Attitudes and Acceptability - Synthesis Report, UK Energy Research Centre, London, n.d.

[100] S.J. Darby, E. McKenna, Social implications of residential demand response in cool temperate climates, Energy Policy. 49 (2012) 759-769. https://doi.org/10.1016/j.enpol.2012.07.026.

[101] M. Broman Toft, G. Schuitema, J. Thøgersen, The importance of framing for consumer acceptance of the Smart Grid: A comparative study of Denmark, Norway and Switzerland, Energy Res. Soc. Sci. 3 (2014) 113-123. https://doi.org/10.1016/j.erss.2014.07.010.

[102] B.K. Sovacool, D.J. Hess, S. Amir, F.W. Geels, R. Hirsh, L. Rodriguez Medina, C. Miller, C. Alvial Palavicino, R. Phadke, M. Ryghaug, J. Schot, A. Silvast, J. Stephens, A. Stirling, B. Turnheim, E. van der Vleuten, H. van Lente, S. Yearley, Sociotechnical agendas: Reviewing future directions for energy and climate research, Energy Res. Soc. Sci. 70 (2020) 101617. https://doi.org/10.1016/j.erss.2020.101617.

[103] W. Throndsen, M. Ryghaug, Material participation and the smart grid: Exploring different modes of articulation, Energy Res. Soc. Sci. 9 (2015) 157-165. https://doi.org/10.1016/j.erss.2015.08.012. 
[104] M. Hansen, B. Hauge, Scripting, control, and privacy in domestic smart grid technologies: Insights from a Danish pilot study, Energy Res. Soc. Sci. 25 (2017) 112-123. https://doi.org/10.1016/j.erss.2017.01.005.

[105] M. Radenković, Z. Bogdanović, M. Despotović-Zrakić, A. Labus, S. Lazarević, Assessing consumer readiness for participation in IoT-based demand response business models, Technol. Forecast. Soc. Change. 150 (2020) 119715. https://doi.org/10.1016/j.techfore.2019.119715.

[106] R. Owen, P. Macnaghten, J. Stilgoe, Responsible research and innovation: From science in society to science for society, with society, Sci. Public Policy. 39 (2012) 751-760.

https://doi.org/10.1093/scipol/scs093.

[107] B.K. Sovacool, D.J. Hess, R. Cantoni, Energy transitions from the cradle to the grave: A metatheoretical framework integrating responsible innovation, social practices, and energy justice, Energy Res. Soc. Sci. 75 (2021) 102027. https://doi.org/10.1016/j.erss.2021.102027.

[108] T.M. Skjølsvold, M. Ryghaug, W. Throndsen, European island imaginaries: Examining the actors, innovations, and renewable energy transitions of 8 islands, Energy Res. Soc. Sci. 65 (2020) 101491. https://doi.org/10.1016/j.erss.2020.101491.

[109] L. Schick, B.R. Winthereik, Innovating Relations - or Why Smart Grid is not too Complex for the Public, Technol. Stud. (n.d.) 21.

[110] T.M. Skjølsvold, M. Ryghaug, T. Berker, A traveler's guide to smart grids and the social sciences, Energy Res. Soc. Sci. 9 (2015) 1-8. https://doi.org/10.1016/j.erss.2015.08.017.

[111] T.H. Christensen, F. Friis, M. Ryghaug, T.M. Skjølsvold, W. Throndsen, S.R. Fernandez, E.S. Perez, Recommendations and criteria for the design of smart grid solutions for households: Lessons learned for designers and policy makers from the IHSMAG project, (2016). https://vbn.aau.dk/en/publications/recommendations-and-criteria-for-the-design-of-smart-gridsolutio (accessed December 17, 2020).

[112] K. Burchell, R. Rettie, T.C. Roberts, Householder engagement with energy consumption feedback: the role of community action and communications, Energy Policy. 88 (2016) 178-186. https://doi.org/10.1016/j.enpol.2015.10.019.

[113] S. Nyborg, I. Røpke, Constructing users in the smart grid - insights from the Danish eFlex project, Energy Effic. 6 (2013) 655-670. https://doi.org/10.1007/s12053-013-9210-1.

[114] P. Devine-Wright, Energy citizenship: Psychological aspects of evolution in sustainable energy technologies, in: Gov. Technol. Sustain., Earthscan, Camden, 2007.

[115] M. Ryghaug, T.M. Skjølsvold, S. Heidenreich, Creating energy citizenship through material participation, Soc. Stud. Sci. 48 (2018) 283-303. https://doi.org/10.1177/0306312718770286.

[116] Y. Strengers, Peak electricity demand and social practice theories: Reframing the role of change agents in the energy sector, Energy Policy. 44 (2012) 226-234. https://doi.org/10.1016/j.enpol.2012.01.046.

[117] N. Marres, The Issues Deserve More Credit: Pragmatist Contributions to the Study of Public Involment in Controversy, Soc. Stud. Sci. 37 (2007) 759-780.

[118] T. Hargreaves, M. Nye, J. Burgess, Making energy visible: A qualitative field study of how householders interact with feedback from smart energy monitors, Energy Policy. 38 (2010) 61116119. https://doi.org/10.1016/j.enpol.2010.05.068. 
[119] L. Ingeborgrud, S. Heidenreich, M. Ryghaug, T.M. Skjølsvold, C. Foulds, R. Robison, K. Buchmann, R. Mourik, Expanding the scope and implications of energy research: A guide to key themes and concepts from the Social Sciences and Humanities, Energy Res. Soc. Sci. 63 (2020) 101398. https://doi.org/10.1016/j.erss.2019.101398.

[120] N. Marres, Material Participation: Technology, the Environment and Everyday Publics | N. Marres | Palgrave Macmillan, 2012. https://www.palgrave.com/gp/book/9780230232112 (accessed December 17, 2020).

[121] I.F. Fjellså, A. Silvast, T.M. Skjølsvold, Justice aspects of flexible household electricity consumption in future smart energy systems, Environ. Innov. Soc. Transit. 38 (2021) 98-109. https://doi.org/10.1016/j.eist.2020.11.002.

[122] M. Nussbaum, A. Sen, The Quality of Life, Oxford University Press, Oxford, 1993.

[123] B.K. Sovacool, M.H. Dworkin, Energy justice: Conceptual insights and practical applications, Appl. Energy. 142 (2015) 435-444. https://doi.org/10.1016/j.apenergy.2015.01.002.

[124] C.A. Miller, A. Iles, C.F. Jones, The Social Dimensions of Energy Transitions, Sci. Cult. 22 (2013) $135-148$.

[125] A. Hirsch, Y. Parag, J. Guerrero, Microgrids: A review of technologies, key drivers, and outstanding issues, Renew. Sustain. Energy Rev. 90 (2018) 402-411.

https://doi.org/10.1016/j.rser.2018.03.040.

[126] C.J. Brown, N. Markusson, The responses of older adults to smart energy monitors, Energy Policy. 130 (2019) 218-226. https://doi.org/10.1016/j.enpol.2019.03.063.

[127] A. McCabe, D. Pojani, A.B. van Groenou, The application of renewable energy to social housing: A systematic review, Energy Policy. 114 (2018) 549-557. https://doi.org/10.1016/j.enpol.2017.12.031.

[128] F. Shirani, C. Groves, K. Henwood, N. Pidgeon, E. Roberts, 'I'm the smart meter': Perceptions of smart technology amongst vulnerable consumers., Energy Policy. 144 (2020) 111637. https://doi.org/10.1016/j.enpol.2020.111637. 